\title{
Relações entre acessibilidade e colaboração em três ambientes virtuais
}

\author{
Alessandro Jatobá (FIOCRUZ) \\ https://orcid.org/0000-0002-7059-6546 \\ Bianca Martins (PUC-Rio) \\ https://orcid.org/0000-0001-7550-2775 \\ Mariana Lopes da Silva (Professora da Rede Estadual de Ensino) \\ https://orcid.org/0000-0003-0442-7389 \\ Vanessa França da Silva (Professora da Rede Estadual de Ensino) \\ https://orcid.org/0000-0002-8770-2990
}

\section{Resumo}

Esta pesquisa tem como objetivo investigar se os problemas de acessibilidade afetam a colaboração por participantes com deficiência visual em três ambientes virtuais averiguados. Para tal, a análise da acessibilidade destas ferramentas foi realizada de dois modos: com o uso ferramentas de validação automática, e validação com usuário real. Participaram do processo uma professora cega e uma estudante com baixa visão. A partir dos resultados das validações, foi possível identificar que nem todo problema de acessibilidade implicará dificuldade na colaboração. Contudo, os problemas referentes à descrição de botões, links, formulários, imagens e vídeos não somente obstaculizam a colaboração, como também impedem a utilização autônoma dos ambientes.

Palavras-chave: Acessibilidade. Colaboração. Ambientes virtuais. Deficiência visual.

Data de submissão: 11/09/2018

Data de aprovação: 16/10/2018

\section{Abstract}

This research aims to investigate if the accessibility problems affect the collaboration among the participants with visual impairment in three checked virtual environments. For such, those tools accessibility analysis was performed in two ways: by the use of Web Accessibility Automatic Evaluation Tools, and real user evaluation. The participants of this process were a Blind Teacher and a student with low vision. From these evaluation results, it was possible to identify that neither every accessibility issue will imply in difficulty on collaboration. However, not only do the problems involving buttons description, links, forms, images and videos get in the way of collaboration, but they also prevent the autonomous use of these environments.

Keywords: Accessibility. Collaboration. Virtual environments. Visual impairment. 


\section{Introdução}

A inclusão de pessoas com deficiência nos mais diversos espaços é um tema que tem tido certa evidência e discussão, haja vista o tema da redação do ENEM 2017 e apontamentos da ONU ${ }^{1}$, que apontam ser este processo fundamental para a implementação da Agenda 2030. Tal discussão ganhou força, principalmente, após a Lei Brasileira de Inclusão da Pessoa com Deficiência (Estatuto da Pessoa com Deficiência) entrar em vigor em 6 de julho de 2015.

A lei supracitada estabelece no seu $3^{\circ}$ artigo, inciso I, que acessibilidade deve permitir o alcance e possibilitar que pessoas com deficiência e mobilidade reduzida utilizem, de forma segura e autônoma, os espaços, mobiliários, equipamentos urbanos, edificações, transportes, informação e comunicação inclusive seus sistemas e tecnologias e quaisquer outros serviços abertos ao público ou coletivos, sejam eles públicos ou privados não importando a localização. (BRASIL, 2015)

Como forma de garantir isto na Web, foram criadas normas. Assim, o eMAG (Modelo de Acessibilidade em Governo Eletrônico) sugere que alguns passos sejam seguidos para a avaliação da acessibilidade de uma página da internet, são eles: validar os códigos do conteúdo HTML e das folhas de estilo; verificar o fluxo de leitura da página; realizar a validação ${ }^{2}$ automática de acessibilidade utilizando o ASES (Avaliador e Simulador de Acessibilidade em Sítios) e outros avaliadores automáticos; realizar a validação manual e o teste com usuários reais. (BRASIL, 2014) O documento ainda aponta que apenas a avaliação com validadores automáticos não é suficiente para determinar se uma página é acessível;

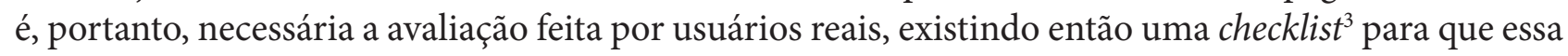
análise seja feita.

Portanto, para que seja possível propiciar a utilização segura e autônoma de ferramentas no âmbito educacional, faz-se necessário estudar se os recursos existentes, mais especificamente os ambientes virtuais de aprendizagem, estão acessíveis para as pessoas com deficiência. Alguns ambientes foram selecionados como alvos desta investigação: CANVAS LMS, MindMeister e Khan Academy. Os três estão disponíveis online e podem ser acessados gratuitamente. Sua escolha se deu devido à necessidade de compreender se estes ambientes cada vez mais frequentes nas práticas educacionais e com visibilidade crescente são acessíveis para pessoas com deficiência visual.

Decidiu-se analisar como se dá a colaboração nesses ambientes com base nos elementos comunicação, cooperação, coordenação e percepção e não apenas investigar pura e simplesmente sua acessibilidade.

Para que a colaboração aconteça, é necessário que as pessoas envolvidas possam trocar informações de alguma maneira, ou seja, tem que haver comunicação. Essas trocas carecem de gerenciamento, então é preciso que haja algum tipo de organização e disposição das tarefas a serem executadas. Este é o papel da coordenação, e as pessoas envolvidas têm, ainda, de trabalhar em conjunto em um espaço compartilhado, devendo haver cooperação e, por fim, para que se informem em relação ao que está acontecendo, ao que outras pessoas estão fazendo e às informações para a execução das suas tarefas, é necessário que haja percepção. (FUKS, 2013, grifo nosso)

A acessibilidade permite que as pessoas com deficiência utilizem os recursos com certa autonomia e, portanto, possibilita que a colaboração entre os usuários, quaisquer que sejam eles, seja favorecida. Todavia, surge uma inquietação: que problemas na acessibilidade podem dificultar a colaboração?

\footnotetext{
1 Disponível em: https://nacoesunidas.org/onu-inclusao-de-pessoas-com-deficiencia-e-fundamental-para-a-implementacao-da-agenda-2030/

2 Entende-se, aqui, como validação, o teste que comprova a concordância com padrões preestabelecidos no contexto de informática.

3 Checklist para teste com usuários reais: https://www.governoeletronico.gov.br/documentos-e-arquivos/eMAG-Checklist-acessibilidade-DV.pdf
} 


\section{Método}

\section{Descrição do método}

O método de triangulação sistemática das perspectivas "refere-se à combinação de perspectivas e métodos apropriados de pesquisa que sejam adequados para considerar tantos aspectos diferentes de um problema quanto possível". (FLICK, 2004, p. 66)

Assim, esta pesquisa, que é um estudo de caso, se utilizou mais de três técnicas de coletas de dados, sendo elas: questionário (checklist), entrevista semiestruturada, observação participante, registro em áudio (através do gravador de voz) e diário de campo e, ainda, dados obtidos através de ferramentas de validação automática de acessibilidade como técnicas de coleta dos dados.

A amostra conta com duas participantes, ambas são pessoas com deficiência visual, sendo uma cega e a outra com baixa visão, abrangendo duas distintas vertentes deste tipo de deficiência.

Os dados foram analisados com base nas relações entre as inferências das participantes e os resultados apresentados pelas ferramentas automáticas através da técnica de triangulação, que "prevê dois momentos distintos que se articulam dialeticamente, favorecendo uma percepção de totalidade acerca do objeto de estudo e a unidade entre os aspectos teóricos e empíricos". (MARCONDES, BRISOLA; 2014, 203).

\section{Etapas da pesquisa}

A primeira etapa foi a realização de uma curadoria entre as ferramentas encontradas para validação automática da acessibilidade, sendo selecionadas Tota11y e ASES. Esta curadoria foi realizada com base em pesquisas em sites de busca acerca de ferramentas variadas para avaliação automática da acessibilidade de websites, fossem elas softwares a serem instalados no computador, plug-ins para navegadores web ou sites próprios para esta finalidade. Estas duas ferramentas foram selecionadas por apresentarem resultados mais detalhados em relação aos problemas de acessibilidade dos websites e por funcionarem adequadamente nos três ambientes investigados.

Em seguida, cada uma das ferramentas foi aplicada nos três ambientes virtuais aqui analisados: CANVAS LMS, MindMeister e Khan Academy, obtendo resultados que foram salvos em formato de imagens (prints) ou texto (pdf) no computador para posterior análise.

A próxima etapa foi, com base no eMAG e nos elementos de colaboração, a elaboração de um questionário para validação da acessibilidade por usuários reais destes três ambientes, chamado aqui de checklist.

Foram convidadas, então, duas pessoas para participar: uma professora cega e uma estudante com baixa visão.

A professora em questão é formada em Pedagogia e possui mestrado na área da educação, e a estudante cursa o sétimo ano do ensino fundamental e tem 20 anos de idade. Ambas concordaram em participar voluntariamente da avaliação, e cada uma levou cerca de 3 horas para analisar as três ferramentas.

Ao aplicar o checklist, elaborado dentro do Google formulários, as questões foram lidas para elas, por preferência de ambas, para que se facilitasse o processo, tendo em vista que elas estariam analisando a ferramenta e não conseguiriam responder ao questionário simultaneamente de forma autônoma, tendo que fazê-lo posteriormente - o que demandaria mais tempo e poderiam se esquecer de algo ou 
não se atentar à alguma questão.

Como as perguntas estavam sendo lidas, o que permitia certas inferências delas, não se limitando às opções de respostas do checklist, além de questionário, tornou-se uma entrevista, que foi registrada através de gravação de voz no smartphone e apontamentos em diário de campo.

Todos os testes foram feitos no sistema operacional Windows, versão 10, com o uso do navegador Mozilla Firefox Quantum, versão 57.0. Nas validações realizadas pela professora e pela estudante foi utilizado o leitor de telas NVDA, versão 2017.3.

Ambas as participantes responderam ao questionário na instituição na qual frequentam, no Laboratório de Informática Educativa. Elas foram convidadas a participar pois são usuárias frequentes de tecnologias digitais e de recursos de acessibilidade, dentre eles o NVDA.

O número de participantes foi o relatado pois era necessário que, além da deficiência visual, as pessoas tivessem habilidade no uso de tecnologias digitais para que sua análise fosse mais acurada. Além disso, o tempo demandado para esta análise não era curto o que dificultaria o voluntariado para a participação.

A última etapa da pesquisa foi a análise dos dados, que ocorreu através da relação entre os dados empíricos (das ferramentas automáticas e das participantes) e teóricos (aporte teórico utilizado).

\section{Ferramentas}

Foram utilizadas três ferramentas como suporte.

Duas delas, o Tota $11 y^{4}$ e o ASES $^{5}$ para validação automática dos ambientes virtuais analisados e uma terceira, o $\mathrm{NVDA}^{6}$, um leitor de telas para computador.

\section{Tota11y}

É uma extensão para Mozilla Firefox, desenvolvida por Khan Academy, na qual pode-se visualizar na página corrente como ela lida com tecnologia assistiva ao permitir que o usuário visualize os problemas encontrados em cabeçalhos, contraste de cor, links dos textos, etiquetas ou textos alternativos de imagens. Esta extensão também está disponível para o Google Chrome; contudo, foi utilizada com o Mozilla Firefox.

\section{ASES}

O ASES (Avaliador e Simulador de Acessibilidade em Sítios) é uma ferramenta do governo federal que permite avaliar, simular e corrigir a acessibilidade de páginas, sítios e portais. Está disponível em uma versão para desktop e uma versão online, que foi a utilizada nesta pesquisa.

\section{NVDA}

NVDA (NonVisual Desktop Access - Acesso não-visual à área de trabalho) é um leitor de telas que permite que pessoas cegas e com baixa visão utilizem computadores. Ele lê as informações textuais que aparecem na tela através de um sintetizador de voz. Funciona em ambiente Windows, é gratuito e possui uma compatibilidade maior com o navegador Mozilla Firefox.

4 Disponível em https://addons.mozilla.org/en-US/firefox/addon/tota11y-accessibility-toolkit/

5 Disponível em: http://asesweb.governoeletronico.gov.br/ases/

6 Disponível em: https://www.nvaccess.org/ 


\section{Ambientes Virtuais}

Aliando a inquietação que move esta pesquisa à crescente inserção de ambientes virtuais no âmbito educacional, foram selecionados três deles com distintos objetivos para serem analisados: CANVAS LMS, o MindMeister e o Khan Academy.

1.4.1 CANVAS LMS ${ }^{7}$ : LMS (Learning Management System - Sistema de Gestão de Aprendizagem). É uma forma de simplificar o ensino e o aprendizado, conectando todas as ferramentas digitais que os professores utilizam em um único lugar de fácil acesso.

1.4.2 MindMeister ${ }^{8}:$ É uma ferramenta online de criação de mapas mentais ou mapas conceituais que permite que você capture, desenvolva e compartilhe suas ideias visualmente.

1.4.3 Khan Academy ${ }^{9}$ : é uma ONG educacional criada e sustentada por Salman Khan. Oferece uma coleção grátis de vídeos de matemática, medicina e saúde, economia e finanças, física, química, biologia, ciência da computação, entre outras matérias.

\section{Resultados}

\section{Canvas}

Tota11y: os erros encontrados se referiram a um cabeçalho que está fora de ordem, ao contraste insuficiente em 7 locais da página e ao texto do link que não estava muito claro, o que poderia ser confuso para o leitor de telas.

ASES: 31 erros em marcação, 88 em conteúdo / informação, 1 em Apresentação e Design e 1 em Formulários. Porcentagem ASES 77,91\%.

Professora: Os links funcionam adequadamente, e o site indica a localização do usuário. Não há verborragia: o texto é claro e parágrafos são curtos. Na página de login (acessada pelo convite), ele lê os formulários perfeitamente. Além disso, em “Todos os cursos", no comando "pesquisar" introduziu-se a palavra educação e abriu-se o curso "Introdução à educação aberta”. Dentro dos módulos do curso, ele indica que é um documento, mas quando abre é uma página com o texto inserido nela, o que facilita muito por não ter que fazer download. A página é bem estruturada, e problemas na acessibilidade não afetam a colaboração.

Todavia, há de se salientar que ele não possui atalhos de teclado, o que não foi considerado um problema em si. Não possui âncoras; os gráficos e imagens pelos quais entramos, não possuem descrição. Os arquivos em flash para análise não foram encontrados, nem arquivos para fazer download, nem tabelas, nem mesmo formulários que contivessem captcha. Não há sumário para textos longos, ou sequer mapa do site e dicas de navegação. Além disso, falta a opção de busca no site, excetuando-se a caixa de pesquisa de cursos. O conteúdo não é lido antes do menu.

A professora ainda apresentou uma certa dificuldade em acessar a lista de links pelo comando INSERT + F7, pois o teclado do notebook necessita que clique em FN para que o comando funcionasse (os três botões estão muito distantes). Ela ainda acrescentou: "Eu acredito que estas plataformas de-

\footnotetext{
7 Disponível em: https://www.canvaslms.com/brasil/

8 Disponível em: https://www.mindmeister.com/pt/

9 Disponível em: https://pt.khanacademy.org/
} 
vem pensar sempre na acessibilidade e vislumbrar que as pessoas com deficiência visual podem ser além de alunos, tutores ou formadores / conteudistas."

Estudante: Além de todos os itens do checklist apontados pela professora, a estudante identificou que não há recursos de alterar o tamanho da fonte, como também o contraste. No ícone do Canvas, ele não leva a lugar algum quando clicado. Na caixa de entrada, o botão "escreva uma nova mensagem" não é lido. Além disso, a descrição do vídeo está em uma legenda e não em um texto alternativo, o que pode dificultar saber qual é o vídeo antes de abri-lo. Não tem chat, mas em "discussão" há comunicação. O site não tem problemas de acessibilidade que interfiram na colaboração. Ela achou que o menu principal na esquerda é confuso porque parece se misturar ao menu do curso; caso fosse acima, seria melhor.

\section{MindMeister}

Tota11y: os erros encontrados se referiram ao contraste insuficiente em 18 locais da página, problemas com etiquetas, textos do link e textos alternativos de imagens.

ASES: 45 erros em marcação, 82 em conteúdo / informação e 1 em Formulários. Porcentagem ASES $90,76 \%$.

Professora: Página inicial tranquila: fez a leitura dos links e leu o "acessar" com google. Porém, na página seguinte, solicitou pagamento, além de ela ser toda em inglês. Foi um tanto complicado chegar no stay basic, e presume-se que seria ainda mais complicado se estivesse sozinha. Os links e botões não possuem descrição, logo, não há como utilizar e, sendo assim, a colaboração é totalmente afetada.

Estudante: Não possui barra de rolagem na horizontal, o que dificulta se deslocar pelo mapa. Os botões não estão devidamente identificados. Na barra inicial só se lê "upgrade", o nome do mapa e a caixa de pesquisa - os demais botões não são lidos. Apesar de não possuir botões para ampliar e reduzir a fonte, possui botões de zoom. A falta de descrição dos links e botões afetam todos os aspectos da colaboração.

\section{Khan Academy}

Tota11y: os erros encontrados se referiram a um cabeçalho que está fora de ordem e ao contraste insuficiente em 4 locais da página, além de estar faltando texto alternativo da imagem.

ASES: 3 erros em marcação e 1 em Apresentação e Design. Porcentagem ASES 86,07\%.

Professora: Os links funcionam. Contudo o conteúdo não é aberto na página de navegação atual. Não há atalhos de teclado nem âncoras, nem mesmo localização do usuário num conjunto de páginas. Além disso, carece de descrição das imagens. Apesar de o texto ser claro e ter parágrafos curtos, não encontramos arquivos para download, em flash ou tabelas. No formulário de pesquisa por assunto, não há uma indicação do que fazer para pesquisar - por exemplo, um texto alternativo dizendo que deve clicar em "enter" ou um botão "pesquisar"/ "buscar" logo após o formulário. O título correto dos links nem sempre é dito, e a descrição dos links não é precisa. Apesar da página possuir padronização na sua estrutura, o conteúdo não é lido antes do menu. Não há sumário para textos longos, nem mapa do site, tampouco dicas de navegação. Percebe-se que o site não é favorável à colaboração, pois 
os formulários têm descrições inconsistentes, além de não oferecer segurança nas interações que são feitas no site.

Estudante: não há descrição dos vídeos e imagens, somente legenda, além de algumas partes do site estarem em inglês. No que se refere à colaboração, os comentários funcionam, permitindo a comunicação. Entretanto, não aparecem neles a foto de quem comentou só o nome - o que pode dificultar a percepção. Todavia, a estudante mostrou-se satisfeita com o ambiente.

\section{Discussão}

Como já relatado anteriormente, optou-se pela análise das ferramentas a partir de duas vertentes: validadores automáticos e testes com usuários reais.

Apesar se serem comumente chamadas de ferramentas de validação automática, elas não podem gerar, automaticamente, relatórios completos sobre as conformidades dos guias de acessibilidade. (TANAKA; ROCHA, 2011) Assim, realizar testes com usuários reais provê resultados mais subjetivos, não possíveis de serem extraídos a partir de validadores automáticos e que, por vezes, podem passar despercebidos por avaliadores profissionais em testes de usabilidade. (SANTANA et al., 2010)

Então compreende-se que ainda que os validadores automáticos sejam muito importantes para identificar problemas na construção dos sites, é fundamental realizar a validação com usuários reais.

A observação de cada um dos três ambientes virtuais possibilitou diferentes perspectivas de compreensão de como se dão as análises de acessibilidade com os métodos utilizados.

Em relação ao CANVAS LMS, os validadores automáticos identificaram que possui problemas no contraste e, entre os três ambientes, teve a menor porcentagem no ASES. Porém, a estudante com baixa visão não identificou que as questões apontadas em relação ao contraste fossem relevantes, e as demais dificuldades encontradas não afetam a colaboração. $\mathrm{O}$ ambiente permite que na inserção de vídeos e imagens, o autor possa adicionar um texto alternativo; todos os vídeos e imagens visitados, contudo, não continham esta descrição.

Sobre o MindMeister, apesar de ter tido a maior porcentagem no ASES, os problemas apontados pelas participantes foram cruciais para o acesso ao ambiente e, portanto, para a colaboração. A ausência de descrição nos links, formulários e botões é um fator impeditivo para seu uso efetivo.

No que se refere ao Khan Academy, mais uma vez a falta de descrição foi apontada, mas como ela estava ausente em alguns pontos apenas, não afetou tanto a colaboração. Um dos validadores utilizado (Tota11y) foi desenvolvido pela ferramenta, que apresentou falhas na construção de sua página através da análise deste validador.

Acredita-se que, dada a especificidade do público-alvo desta pesquisa (pessoas com deficiência visual), o caráter da pesquisa (estudo de caso) e a qualidade dos dados extraídos, o número de participantes não invalida as importantes inferências sobre acessibilidade nos ambientes analisados. Deve-se observar, ainda, o fato de que as participantes foram selecionadas por sua familiaridade com uso de tecnologias digitais e acesso à internet e pelos diferentes tipos de deficiência visual (cegueira e baixa visão).

No que se refere ao número de participantes de testes de acessibilidade com usuário reais, boa parte das abordagens documentadas na literatura são limitadas. (RAMOS; DANTAS, 2017) 
Durante o estudo, foi possível observar que os problemas encontrados pelas ferramentas de validação de acessibilidade utilizadas podem não ser considerados entraves por usuários reais e que problemas que, para o validador automático não foram considerados tão relevantes, foram suficientes para afetar não somente a colaboração, mas a utilização do ambiente.

Alguns problemas na acessibilidade referem-se a falhas na construção das páginas; porém, outros se referem ao desconhecimento dos usuários no ato da inserção de imagens ou vídeos, não os descrevendo corretamente.

Uma possível solução é a utilização de texto alternativo (alt text) para descrever uma imagem que carregue alguma informação significativa, tendo certeza que a esta descrição elaborada está compreensível (SOKOLIK, 2018). Para que o usuário não se esquecesse de incluir esta descrição poderia haver uma caixa de diálogo no ato da inserção da imagem ou vídeo que indicasse a necessidade de introdução de uma descrição detalhada do objeto, exemplificando como poderia ser elaborada essa descrição. Caixa de diálogo esta que impediria que o usuário concluísse a inclusão do objeto, caso não inserisse uma informação textual.

Para as pessoas com deficiência visual, os aspectos da colaboração funcionarão de um modo semelhante ao das pessoas sem deficiência, mas com certas limitações. Caso sejam desenvolvidas de forma que seu conteúdo seja disponibilizado num formato adequado e que proporcionem interação de forma apropriada, as ferramentas colaborativas oferecem uma excelente oportunidade paras as pessoas com deficiência visual. (BUZZI; LEPORINI, 2008).

Para acessar o histórico de edições do mapa no MindMeister, por exemplo, são necessários muitos cliques - o que dificulta a percepção para estas pessoas, assim como quaisquer notificações apenas visuais. Mas, no geral, caso os botões, links, formulários, imagens e vídeos possuam as devidas descrições, estas pessoas poderão colaborar satisfatoriamente.

Tendo em vista que os problemas na acessibilidade afetam o acesso às ferramentas, implicando diretamente a colaboração dentro delas, torna-se claro, portanto, o objetivo desta pesquisa, que buscou investigar se os problemas de acessibilidade afetam a colaboração por participantes com deficiência visual em três ambientes virtuais.

\section{Considerações finais}

O intuito deste artigo foi contribuir para os estudos acerca de acessibilidade para pessoas com deficiência visual e colaboração em ambientes virtuais. Todavia, acredita-se que novas pesquisas podem ser realizadas para a obtenção uma análise mais acurada sobre demais questões problemáticas dentro dos ambientes no que se refere à acessibilidade, com um grupo maior de usuários reais, um tempo maior de investigação, além do apoio de um profissional na área de tecnologias da informação especialista em desenvolvimento web e acessibilidade para dar o suporte técnico necessário, podendo, inclusive, propor modificações nos ambientes investigados para torná-los mais acessíveis. Deve-se levar em consideração as implicações que as barreiras de falta de acessibilidade causam na colaboração entre os indivíduos nestes ambientes.

Portanto, considera-se que, apesar de suas limitações, esta pesquisa aponta dados relevantes acerca da relação entre problemas de acessibilidade e colaboração nos ambientes investigados. 


\section{Agradecimento}

À professora Margareth Olegário, Mestre em Educação, que se prontificou a participar desta pesquisa voluntariamente, e à estudante Vanessa Barbosa. Ambas trouxeram riqueza para esta investigação.

\section{Referências}

BRASIL. Ministério do Planejamento, Orçamento e Gestão. Secretaria de Logística e Tecnologia da Informação. eMAG Modelo de Acessibilidade em Governo Eletrônico. Brasília : MP, SLTI, 2014. 92 p.: color. Disponível em: <https://www.governoeletronico.gov.br/documentos-e-arquivos/eMAGv31.pdf>. Acesso em 12 nov. 2017.

BRASIL. Ministério do Planejamento, Orçamento e Gestão. Secretaria de Logística e Tecnologia da Informação. Padrões web em governo eletrônico : cartilha de codificação. Brasília : MP, SLTI, 2010. 48 p.: color. Disponível em: <https://www.governoeletronico.gov.br/documentos-e-arquivos/e-pwg-Codificacao.pdf>. Acesso em 12 nov. 2017.

. Lei no 13.146, de 6 de julho de 2015. Institui a Lei Brasileira de Inclusão da Pessoa com Deficiência (Estatuto da Pessoa com Deficiência). Diário Oficial [da] República Federativa do Brasil. Poder Executivo, Brasília, DF, 06 jul., 2015.

. Presidência da República. Portal da Legislação - Planalto. Disponível em: <http://www. planalto.gov.br/ccivil_03/_ato2015-2018/2015/lei/l13146.htm> . Acesso em: 01 dez. 2017.

BUZZI, Marina; LEPORINI, Barbara. Is Wikipedia usable for the blind?. In: Proceedings of the 2008 international cross-disciplinary conference on Web accessibility (W4A). [S.I] : ACM, 2008. p. 15-22.

CUSIN, César Augusto. Acessibilidade em ambientes informacionais digitais. 2010. Tese (doutorado) - Universidade Estadual Paulista, Faculdade de Filosofia e Ciências, 2010. Disponível em: <http://hdl.handle.net/11449/103359>. Acesso em: 01 dez. 2017.

FLICK, Uwe. Uma introdução à pesquisa qualitativa. Trad. Sandra Netz. 2 ed. Porto Alegre: Bookman, 2004.

FUKS, H., RAPOSO, A.B.; GEROSA, M.A. Do Modelo de Colaboração $3 C$ à Engenharia de Groupware. In: SIMPÓSIO BRASILEIRO DE SISTEMAS MULTIMÍDIA E WEB - WEBMIDIA, 2003. Salvador-BA. Disponível em: <http://groupware.les.inf.puc-rio.br/public/papers/Webmedia2003. pdf $>$. Acesso em 12 nov. 2017.

MARCONDES, Nilsen Aparecida Vieira; BRISOLA, Elisa Maria Andrade. Análise por triangulação de métodos: um referencial para pesquisas qualitativas. Revista Univap, v. 20, n. 35, p. 201-208, 2014.

RAMOS, André Luís Belmiro Moreira; DANTAS, Ana Esther Victor Barbosa. Internet para todos: uma abordagem metodológica para avaliação multidimensional da acessibilidade web. Revista Mangaio Acadêmico, v. 2, n. 1, p. 01-11, 2017. Disponível em: <http://revistaadmmade.estacio. br/index.php/mangaio/article/view/3899>. Acesso em: 01 mar. 2018.

SANTANA, F. V. et al. Um Processo de Avaliação de Acessibilidade Web Universal Aplicado ao Website da Receita Federal: do Código a Testes com Usuários. SIMPÓSIO DE FATORES HUMANOS EM SISTEMAS COMPUTACIONAIS, 9. Belo Horizonte, 2010. Disponível em <https://www. researchgate.net/profile/Vagner_Santana/publication/260887013_Um_Processo_de_Avaliacao_de_Acessibilidade_a_Web_Universal_Aplicado_ao_Website_da_Receita_Federal_do_Co- 
digo_a_Testes_com_Usuarios/links/55ad240708aee079921daee2/Um-Processo-de-Avaliacao-de-Acessibilidade-a-Web-Universal-Aplicado-ao-Website-da-Receita-Federal-do-Codigo -a-Testes-com-Usuarios.pdf>. Acesso em: 2 mar. 2018.

SOKOLIK, Maggie. The nexus of accessibility and pedagogy: what every online instructional designer should know. The Electronic Journal for English as a Second Language, v. 21, n. 4, 2018. Disponível em: <http://www.tesl-ej.org/pdf/ej84/int.pdf>. Acesso em: 5 mar. 2018.

TANAKA, Eduardo Hideki; ROCHA, Heloísa Vieira da. Evaluation of web accessibility tools. In: Proceeding of The Brazilian Symposium on Human Factors in Computing Systems, 10th and The Latin American Conference on Human-Computer Interection, 5th. Brazilian Computer Society, 2011. p. 272-279. 